\title{
ANALISA SISTEM INFORMASI PEMLIHARAAN PRASARANA JALAN DAN JEMBATAN DINAS PEKERJAAN UMUM (PU)
}

\author{
Firna Yenila, Mutiana Pratiwi, Devia Kartika, Rima Liana Gema, Gustiawan Efendi \\ Universitas Putra Indonesia YPTK Padang \\ E-mail : mutiana_pratiwi@upiyptk.ac.id
}

\begin{abstract}
Abstrak
Telah dilakukan penelitian pada Kantor Dinas Pekerjaan Umum (PU) Kabupaten Pasaman Barat dimana permasalahan yang dijadikan sebagai dasar dalam penelitian ini yaitu penyajian informasi Mengenai prasarana Jalan Dan jembatan secara cepat dan tepat. Dengan proses observasi secara langsung kelapangan telah mendapatkan kelemahan sistem yang sedang berjalan. Walaupun tidak secara keseluruhan namun lebih mengarah pada masalah spesifik, tetapi diharapkan dapat membantu permasalahan dalam penyajian informasi prasarana jalan dan jembatan. Penulis merancang sistem informasi dalam pemeliharaan jalan dan jembatan karena dengan sistem informasi ini akan lebih cepat, tepat dan akurat dalam penyajian informasi kepada pihak-pihak berkepentingan dalam Dinas Pekerjaan Umum (PU) Kabupaten Pasaman Barat.
\end{abstract}

Kata Kunci : Sistem, Informasi, Prasarana, Jalan, Jembatan

\section{PENDAHULUAN}

\subsection{Latar Belakang}

Seiring dengan perkembangan ilmu pengetahuan dan teknologi membawa pengaruh yang besar terhadap kehidupan manusia yang megakibatkan terjadinya suatu persaingan dalam mengejar kebutuhan, dengan perkembangan ilmu pengetahuan dan teknologi apalagi di bagian ilmu komputer terdapat perkembangan bahasa pemograman yang memudahkan dalam suatu kegiatan seperti pengolahan suatu data. Dengan perkembangan tersebut dapat mempermudah programer dalam membuat suatu aplikasi berbasis objek dan didukung dengan database yang handal.

Dinas Pekerjaan Umum (PU) Kabupaten Pasaman Barat bergerak dibidang pembangunan daerah dan memperbaiki jalan dan jembatan yang rusak, dimana jalan dan jembatan merupakan akses utama masyarakat banyak dalam melakukan kegiatannya sehari-hari tetapi masih terdapat kendala dan kesulitan dalam pengolahan data terutama bagian data proyek, jalan, jembatan dan beberapa kegiatan lainnya, karena disebabkan belum sepenuhnya adanya penerapan sistem dalam melakukan pengolahan data. Sistem yang dilakukan sekarang masih dirasa kurang optimal dalam pengolahan data proyek, jalan, jembatan dan pembuatan laporan serta pencarian data, sehingga akan timbul permasalahan seperti redudancy data, data yang dihasilkan kurang efektif, kesulitan dalam pencarian data dan sebagainya yang di sebabkan belum adanya sistem yang mendukung dalam penanganan sistem informasi, belum adanya database yang terintegrasi dan mendukung dalam pembuatan infomasi. 

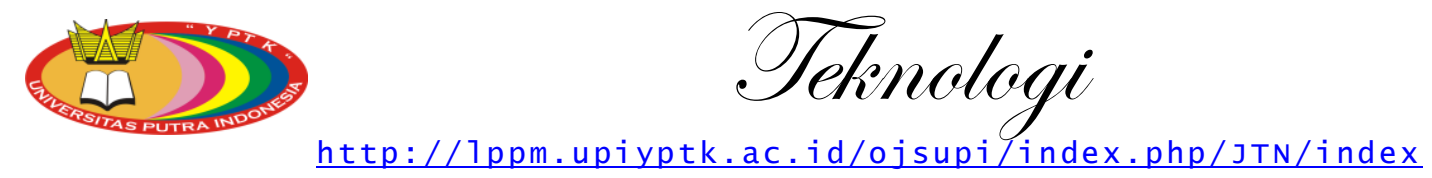

Vol. 9 Issue 12019

$\mathrm{P} \quad$ enelitian ini bertujuan untuk merancang sistem infromasi pada Kantor Dinas Pekerjaan Umum (PU) Kabupaten Pasaman Barat untuk mempermudah pengguna dalam pengolahan data, pembuatan laporan untuk pimpinan, dan mempermudah dalam pencarian data.

\subsection{Tujuan Penelitian}

Adapun tujuan dari penelitian ini adalah

1. merancangan suatu sistem informasi yang akan digunakan untuk mendapatkan hasil berupa informasi yang tepat dan akurat.

2. Penyajian informasi yang lebih baik sehingga memudahkan penyusunan laporan yang dibutuhkan.

\section{LANDASAN TEORI}

\subsection{Konsep Dasar Sistem Informasi}

Sistem informasi manajemen berhubungan dengan informasi. Berapa banyak informasi yang di berikan oleh sebuah sistem informasi. Belum adanya metode untuk mengukur informasi dalam sebuah sistem dan kerumitan informasi tidak memungkinkan adanya suatu rumus atau algoritma untuk menghitung isinya.informasi adalah sebuah istilah yang tepat dalam pemakaian umum. Informasi dapat mengenai data mentah, data tersusun, kapasitas dalam sebuah saluran komunikasi, dan lain sebagainya. Informasi ibarat darah yang mengalir di dalam tubuh suatu organisasi sehingga informasi ini sangat penting di dalam tubuh suatu organisasi sehingga informasi ini sangat penting di dalam suatu organisasi. Suatu sistem yang kurang mendapatkan informasi akan menjadi luruh, kerdil, dan akhirnya mati. ${ }^{[3]}$

\subsection{Defenisi Sistem}

Sistem didefinisikan sebagai sekumpulan prosedur yang saling berkaitan dan saling terhubung untuk melakukan suatu tugaas bersama-sama ${ }^{[1]}$.Sistem adalah sekelompok elemen yang terintegrasi dengan maksud yang sama untuk mencapai tujuan ${ }^{[10]}$.

\subsection{Pengertian Informasi}

Menurut Mcleoad informasi adalah Data yang di olah menjadi bentuk lebih berguna dan lebih berarti bsgi yang yang penerimanya ${ }^{[5]}$.Informasi adalah data yang telah di klasifikasi atau di interpretasi untuk digunakan dalam proses pengambilan keputusan ${ }^{[3]}$

\subsection{Pengertian Sistem Informasi}

Sistem informasi adalah seperangkat komponen yang saling berhubungan dan berintegrasi yang berfungsi memproses, mendistribusikan, serta menyimpan informasi guna mendukung keputusan dan pengawasan di dalam suatu organisasi. ${ }^{[11]}$

\subsection{Basis Data (Database)}

\subsubsection{Pengertian Basis Data (Database)}

Sistem basis data adalah sistem komputerisasi yang tujuan utamanya adalah memlihara data yang sudah diolah atau informasi dan membuat informasi yang tersedia saat dibutuhkan. Pada inti nya basis data adalah media untuk menyimpan data agar dapat diakses dengan mudah dan cepat. ${ }^{[3]}$ 


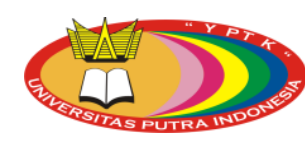

http://1ppm.upiyptk.ac.id/ojsupi/index.php/JTN/index

Vol. 9 Issue 12019

ISSN: 2301-4474| e-ISSN: 2541-1535

\section{METODOLOGI PENELITIAN}

Dalam melakukan penelitian agar mendapat hasil seperti yang diharapkan, maka diperlukan kerangka kerja penelitian, dimana kerangka penelitian yang dilakukan digambarkan seperti Gambar 3.1.

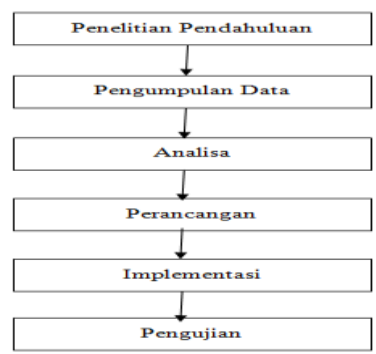

Gambar 3.1 Kerangka Penelitian

\section{ANALISA DAN PERANCANGAN}

\subsection{Analisa Sistem}

Analisa sistem merupakan tahap awal dalam perancangan dan pengembangan sebuah sistem yang akan dirancang, karena pada tahap inilah akan diukur dan dievaluasi kinerja dari sistem yang dirancang, identifikasi terhadap masalah-masalah yang ada dan langkah-langkah untuk kebutuhan perancangan yang diharapkan. Dalam melakukan analisis sistem terlebih dahulu harus mengetahui dan memahami sistem, untuk menganalisa sistem diperlukan data dari sistem untuk dianalisa. Data yang diperlukan adalah hal-hal yang berkenaan dengan defenisi data tersebut.

\subsection{Analisa Sistem Yang Sedang Berjalan}

Sebelum mengembangkan sistem yang baru maka terlebih dahulu kita harus paham terhadap sistem yang telah ada, hal ini dilakukan untuk mengetahui kekurangan-kekurangan yang terjadi dan masalah-masalah yang ditemukan pada sistem tersebut. Penelitian ini memfokuskan untuk mengetahui terhadap masalah yang berhubungan dengan sistem infomasi Dinas Pekerjaan Umum (PU) Kabupaten Pasaman Barat.

\subsection{Kelemahan Sistem Yang Sedang Berjalan}

Penyampaian informasi Dinas Pekerjaan Umum (PU) Kabupaten Pasaman Barat pada saat sekarang ini terdapat beberapa kelemahan. Kelemahan-kelemahan tersebut adalah:

1. Penyajian Informasi yang masih dilakukan dengan pengetikan menggunakan microsoft exel, yang mana masih di temukan kesalahan-kesalahan dalam pengetikan mengenai infomasi dalam pemeliharaan prasarana jalan dan jembatan.

2. Penyimpanan informasi yang belum memiliki database sehingga sering kesulitan mencari data informasi yang dibutuhkan.

\section{IMPLEMENTASI SISTEM}

Tahap implementasi sistem merupakan salah satu tahap dalam daur hidup pengembangan sistem, dimana tahap ini merupakan tahap agar sistem informasi siap untuk dipakai. Dalam tahap ini berlangsung beberapa aktifitas secara berurutan yakni mulai dari 


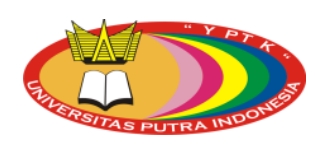

menerapkan rencana implementasi, melakukan kegiatan implementasi, dan tindak lanjut implementasi.

Supaya implementasi berjalan dengan baik dan sesuai dengan yang diharapkan, maka suatu rencana implementasi perlu dibuat terlebih dahulu. Rencana implementasi ini dimaksudkan untuk mengatur biaya serta waktu yang dibutuhkan selama tahap implementasi.

\subsubsection{Menu Utama}

Layout ini merupakan interface utama yang akan digunakan oleh pengguna aplikasi. Terdiri dari login, profil, struktur organisasi. Tampilan menu utama dapat dilihat pada Gambar 4.1 berikut ini:

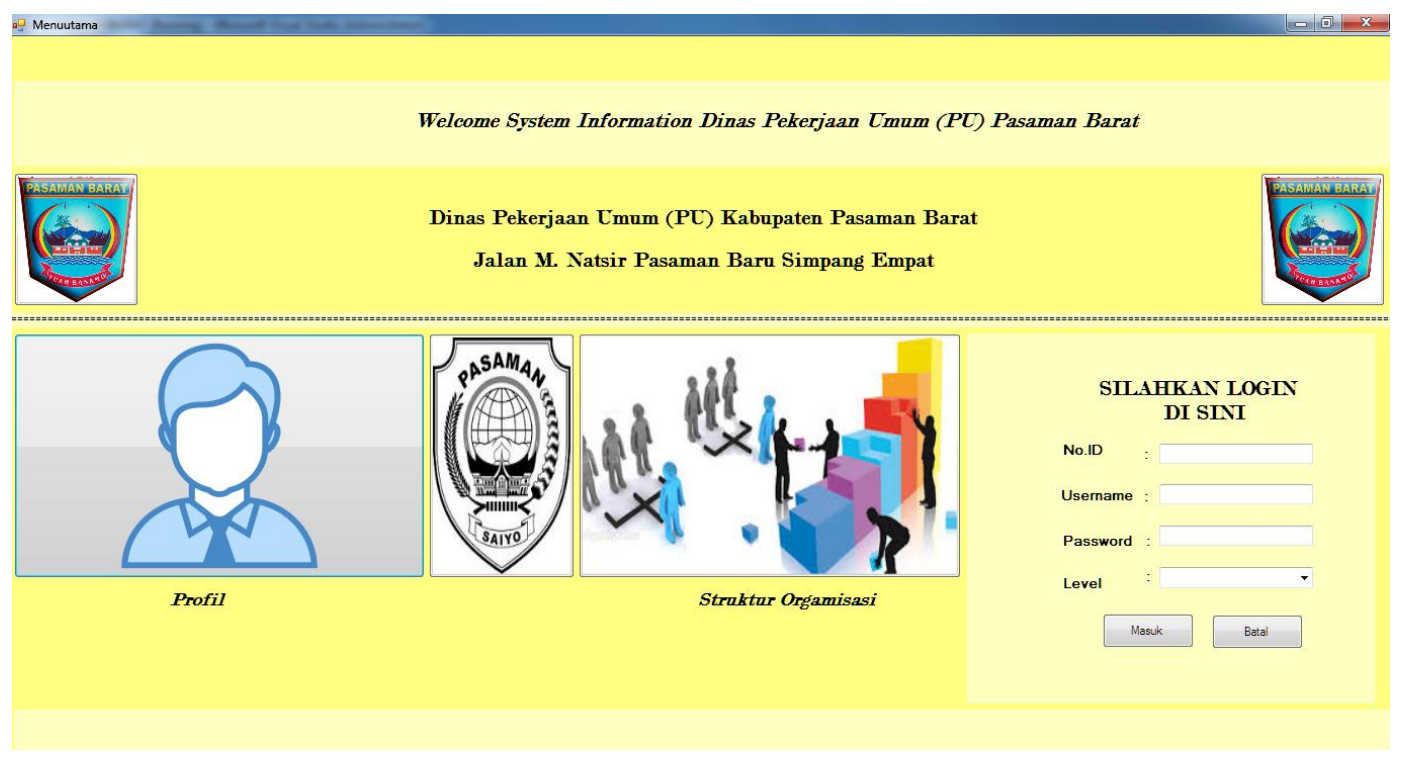

Gambar 5.1 Home Utama

\section{PENUTUP}

\subsection{Kesimpulan}

Berdasarkan dari penelitian yang telah penulis lakukan pada Dinas Pekerjaan Umum (PU) Kabupaten Pasaman Barat maka dapat diambil kesimpulan sebagai berikut :

1. Dengan diterapkannya sistem informasi pengelolaan data yang komputerisasi akan mengatasi masalah yang dihadapi.

2. Dengan adanya sistem informasi ini lebih efesiensi dalam pengolahan data proyek, jalan dan jembatan serta pembuatan laporan lebih jelas dan akurat.

\subsection{Saran}

Berdasarkan kesimpulan diatas, maka dapat diberikan saran-saran sebagai berikut : 


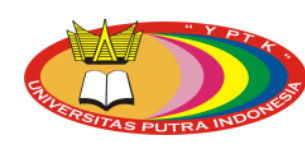

http://1ppm.upiyptk.ac.id/ojsupi/index.php/JTN/index

1. Implementasikan sistem yang baru tidak dilakukan secara mendadak, tetapi terlebih dahulu dilakukan penyesuaian kepada bagian administrasi dan karyawan yang berperan di dalam penggunaan sistem yang baru di rancang ini.

2. Diadakan pelatihan bagi admin dan karyawan yang akan mengelola sistem baru atau merekrut tenaga kerja baru yang professional di bidang komputer.

3. Perlunya dilakukan pemeliharaan (maintance) dan pengembangan sistem di masa akan datang untuk menjaga kelangsungan hidup sistem tersebut sesuai dengan kebutuhan informasi yang terus berkemban

\section{DAFTAR PUSTAKA}

[1] Pratama, I Putu Agus Eka. 2014. Sistem Informasi dan Implementasinya. Informatika, Bandung.

[2] Sutabri, Tata. 2012. Konsep Sistem Informasi. Andi, Yogyakarta.

[3] M.Shalahuddin, Rosa A.S.2013. Rekayasa Perangkat Lunak. Informatika, Bandung.

[4] Hidayatullah, Priyanto.2015. Visual Basic .NET Membuat Aplikasi Database dan Program Kreatif. Informatika, Bandung.

[5] Yakub.2012.Pengantar Sistem Informasi : Graha Ilmu.

[6] Afyenni, Rita.2014. "Perancangan Data Flow Diagram untuk Sistem Informasi Sekolah (Studi Kasus pada SMA Pembangunan Laboratorium UNP)”. Jurnal TEKNOIF, Vol. 2, No. 1, April 2014, ISSN : 2338-2724.

[7] Saputra, Rusli. 2015. "Desain Sistem Informasi Order Photo Pada Creative Studio Photo Dengan Menggunakan Bahasa Pemrograman Visual Basic.Net 2010”. Jurnal Momentum Vol.17 No.2, Agustus 2015, ISSN : 1693-752X.

[8] Purnamayudhi, Onny dan Eko Budi Satoto.2014. “Aplikasi Sistem Informasi Penjualan Apotek”. Jurnal Teknik Industri, ISSN : 1411-6340.

[9] Firdaus. 2014. "Sistem Informasi Akademis (SIA) Sekolah Menengah Kejuruan (SMK) Cendana Padang Panjang Dengan Menggunakan Bahasa Pwmograman Yang Berbasis Object Oriented Programing (OOP)", Jurnal KomTekInfo Fakultas Ilmu Komputer, Volume 1, No. 2, Desember 2014. ISSN : 2356-0010.

[10] Machmud, Rizan. 2013. "Peranan Penerapan Sistem Informasi Manajemen Terhadap Efektivitas Kerja Pagawai Lembaga Pemasyarakatan Narkotika (Lapastika) Bollangi Kabupaten Gowa". Jurnal Capacity STIE AMKOP Makasar Vol. 9, No. 3, September 2013, ISSN : 1907-3313.

[11] Iswandy, Eka.2015. "Sistem Penunjang Keputusan Untuk Penerima Dana Santunan Sosial Anak Nagari Dan Penyaluran Bagi Mahasiswa Dan Pelajar Kurang Mampu Dinagari Barung- Barung Balantai Timur", Jurnal TeknoIF.Vol. 3 NO. 2 Oktober 2015 ISSN:2338-2724. 


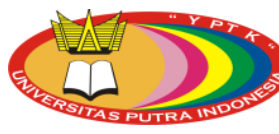

